\title{
Assessment of the Competencies of Supervisors and their Roles in Primary and Secondary Schools of Sidama Zone, Ethiopia
}

\author{
Eshetu Mandefro \\ College of Education, Hawassa University, \\ Ethiopia
}

\begin{abstract}
The study was aimed to analyze the competencies and roles of supervisors in primary and secondary schools of Sidama zone. The dimensions of supervision used in the study to investigate the skills of supervisors and their roles were considered that supervisors as a change agent, builders of positive school cultures and implementers of different supervisory principles on the specific contexts of each school to boost the education quality improvement at the study areas. A descriptive survey research design with qualitative and quantitative methods was used. The study consists of 381 primary and secondary school principals and teachers. Data was collected using questionnaires and semi-structured interviews. The data were analyzed using descriptive and inferential statistics. As results revealed there are negative correlations between supervisors' skills, competency, and knowledge as a change agent, creating positive school culture and application of different supervisory principles in the context to which they are working. Finally, based upon the findings it was concluded that improving the professional competence of supervisors has immense contribution in enhancing school improvement, reform and creating a positive school culture and change, as a result, the quality of education in primary and secondary schools will be improved. In the light of these results, I recommend (1) there should have legal policies and initiation for distinguished individuals like school principals, senior teachers to come to supervisory position in primary and secondary schools, (2) there should have training courses and workshops for supervisors on the contemporary issues of global education, supervision trends to build their skills; and (3) develop and provide standard supervision manuals for school supervisors so that they can use the material to improve their day to day supervisory activities.
\end{abstract}

Keywords: competencies of supervisors, skills of supervisors, change agent, school culture, supervisory principles.

\section{Rationale}

In the process of teaching and learning the instructional competencies of teachers is a very significant area to realize the quality of instruction. In this regard, supervisory staffs are expected to play immense roles to promote and improve the instructional competencies of teachers in educational organizations, which is the ultimate goal of supervision in education. As it is recognized by many kinds of literature; the primary aims of supervision in education are to guide and support the implementation of curricular activities; scrutinize the processes of instruction, 
provide guidance and counseling services to teachers on the improvements of the teachinglearning processes in a classroom. It is the roles of supervisors to conduct formative assessments of the students' learning and balance the actual outcomes of learning with expected targets, ensure the pleasing progress in competencies of teachers for the advancement of conceptual knowledge and teaching skills. A supervision service in educational organizations is also a means to facilitate the enhanced performance in teachers' pedagogical practices for the advancements of the students' learning outcomes in the schools. (Habtamu \& Eshetu, 2019; Kotirde \& Bin, 2014; Sule, 2013; Gregory, 2011; Unal \& Erol, 2011; Nolan \& Hoover, 2008; Starratt, 2008; UNESCO, 2007; Sergiovanni \& Starratt, 2007; Certo, 2006).

It is believed that an effective supervision service in whole systems of schools will facilitate the achievement of broad goals of education at primary, secondary and tertiary levels. Today's quality of education recession in Ethiopia calls for the effective and efficient utilization of scarce resources available in educational organizations. Recognizing the fact that Daresh (2001) explained the importance of supervision services in education as it is a powerful means to lead study and improve the entire system of educational organizations. This indicates that effective supervision services of schools are a very important area of leadership in education for the achievement of educational goals and objectives, which is a national priority in Ethiopia.

Today schools in all countries are expected to become more flexible, responsible and capable of adapting well organized and structured supervision services. This is because of the following reasons, quality control through supervision is a critical area for policymakers, the huge amount of money vested to education should be supervised; quality of education is declining, schools are autonomous for their activities which need intensive supervision and support system (UNESCO, 2007). Likewise, the World Bank (2010) stated that systems of supervision and support to schools are areas of improvement to be employed by world nations to advance educational results and solve problems related to international educational strategies. It has also been put by IIEP (2007); the total system of education in the world has to be supported by supervision services to get better instructional processes and the academic achievements of the students.

It has been more than eight decades since educational supervision/inspection was introduced into the Ethiopian education system. That is, the practice of supervision in this country is so long. However, experience shows that the concern of supervision in these years has been more administrative than academic. In support of the above idea, the Ethiopian Ministry of Education (1987) writes that from among fifteen tasks listed to be performed by the office of inspectorates at various levels; those that have direct relevance to professional and pedagogical assistance were found to be only three. All the rest $(80 \%)$ of the inspectors' activities were administrative, financial, and property and utility management. Basically, there are different supervisory positions and structures in public primary and secondary schools all over the country such as school based supervision, cluster supervision, woreda/district education office supervision/inspection, and so on. But the experience shows that most of the supervisors assigned on different positions are not efficient and effective in supporting and guiding teachers to improve the teaching-learning process in the schools they are belongs.

The supervision service in education has significant roles to achieve the broad goal of education and quality improvement all over the system. Whether or not, the improvement of teaching and learning and students' overall achievements are directly or indirectly dependent on the provision of good supervision service. The major reason to conduct this study is that, to the best knowledge of the investigator, there has been no research account made recently in the study areas that shows the competencies of supervisors and their roles at primary and secondary 
schools. Similarly, the extent to which supervisors act as change agents, school culture promoters and applying supervisory principles in the different contexts of schools was also not investigated.

Most of the time, educational supervision delivered to teachers is aimed to maintain better experience, impart new knowledge and skills, and develop a positive attitude towards educating the young generation. Although the importance of supervisory services provided to teachers to improve instruction and quality of education is not denied by many, the actual movement in favor of it and its practical aspect seems limited in the government primary and secondary schools of Sidama zone today. It appears that teachers are not properly supported by supervisors in managing problems they encountered in the course of improving instruction to achieve educational objectives. In support of this, Boardman (1993) stated that "there is much indirect evidence that supervision services today more in theory than practice and in many primary and secondary schools there is no systematically functioning supervisory program or activity." Furthermore, primary and secondary school teachers of the zone seem inefficient in their instructional activities which might be related to the poor application of educational supervision.

Generally, failure in the quality of education expressed by many educational experts may also be attributed partly to the poor provision of supervisory services. On the other hand, educational supervision by its nature is not an easy task to accomplish as desired. However, according to Boardman (1993), many of the elements operating to limit the development of effective supervision may not be obstacles inherent like supervision or are the factors that should be permitted to limit supervisory efficiency or the possibility of supervisory program. Hence, this study aimed to analyze the competencies of supervisors and their roles on the three dimensions of supervision such as change agent, build positive school culture and application of sound supervision principles to improve the quality of teaching-learning process in primary and secondary schools of Sidama zone, Ethiopia.

\section{Materials and Methods}

\section{Research Design and Method}

The study employed a descriptive survey design; since it enables to get detail empirical evidence to collect, the process analyzes and presents the data to achieve the objectives of the study. The design is preferred as Gay et al. (2009) suggested that it enables researchers to collect adequate shreds of evidence, answer detail questions, and obtain reliable information about the issue in the study area.

As the study deals with different variables that might have a direct relationship with supervisory activities in the study area, a descriptive survey research design is preferred to explicitly describe the scenarios on the ground. Similarly; the study was used a mixed-method; because this method is used to triangulate qualitative and quantitative data and information obtain from different sources. The mixed-method is a pragmatic paradigm used to analyze qualitative and quantitative data with multiple viewpoints.

\section{Population, Samples Size, and Sampling Techniques}

The population of this study was comprised of a total of 52 primary and secondary schools found in eight rural local administrative districts, and 4 town administrations in the Sidama zone. Among these schools 29 of them were primary and the other 23 were secondary schools. The schools were selected through a multi-stage stratified random sampling technique. Regarding subjects of the study, a total of 1034 teachers were working at sampled primary and secondary schools during data collection. From each school, 30\% of school teachers were selected by stratified proportionate sampling techniques. As a result, 189 primary school and 131 secondary 
school teachers participated in the study. Besides, 38 primaries and 23 secondary school principals were also involved in the study.

\section{Data Gathering Instruments}

\section{Questionnaire}

A questionnaire was considered as one of the most appropriate instruments for this study since the study covered a wide range of areas and relatively larger samples that can't be fully reached through other tools (Kendall, 2008). In this regard, the questionnaires were designed for school principals and teachers whose number is relatively larger.

\section{Interview}

The interview was used by the researcher to get additional data to substantiate the information obtained by questionnaires. In this regard, semi-structured interview questions were prepared and administered to senior school principals and deputy principals, department heads, and senior teachers about competencies and roles of supervisors in their schools. This is because Cohen, et al, (2002), stated that, this live form of data collection involves recording data as the interview and that takes place or shortly afterward.

\section{Methods of Data Analysis}

Data collected from the survey were entered into a computer for analysis mainly using Microsoft Excel and statistical package for social sciences (SPSS V.20). Before running the analysis some internal consistency checks were made to assess the quality of the data. To analyze the quantitative data, both descriptive and inferential statistics were used. The descriptive analysis such as mean score, frequency, standard deviation, and the percentage was used to guide the analysis of the data. In this respect, Best and Kahn (2003) have argued that mean and percentage is probably the most satisfactory measure for characterizing a group. The data collected through interviews were analyzed, narrated, and organized systematically. Also, the qualitative narrative written techniques were used. To test the strength of the relationship between two groups of respondents, compute mean comparisons, and decide upon determinant factors, $\mathrm{p}$-value and ttest were used.

The purpose of school supervision is providing guidance and support in administrative and pedagogical areas primarily concerned with improving the teaching-learning process. To transform the quality of education through improved instructional practices and competencies of teachers', supervisors are expected to perform diversified activities in educational organizations. Among the activities to be executed by supervisors to realize institutional reforms, the quality instruction, and competencies of teachers; supervisors should act as a change agent, promote positive school cultures in the schools they are assigned, identify and apply different supervisory principles in the school context and work with stakeholders to maximize students' learning.

Supervisors have to play a great role in promoting instruction, curriculum and staff development. However, this study focused on three dimensions of supervisory roles such as change agent, promote positive school culture, identify and apply different supervisory principles in the school context and work with stakeholders to maximize students' learning were the major concerns used through this study to analyze the competency of supervisors and their roles in primary and secondary schools of Sidama Zone. 
Under each dimension of supervision different supervisory roles were listed and principals and teachers asked to indicate the competencies and performance of supervisors at their schools. Hence to rate and evaluate the competency and performance of supervisors' roles and functions, the respondents' opinions were obtained using five points' frequency Likert type items summarized into three rating scales such as agree, undecided and disagree. Meanwhile, the statistical tools used to measure responses of respondents were mean, standard deviation, t-test, and $\mathrm{p}$-value.

The mean values in the following tables were interpreted as follows. If the mean value in the table is between $1-2.99$ indicates that respondents' disagreement on role of supervisors in their school; if the mean value in the table is 3.00 indicates that respondents are unable to decide on role of supervisors in their school; finally, if the mean value in the table is between $3.01-5.00$ indicates that respondents' agreement on role of supervisors in their school. Moreover, the data obtained through interviews were analyzed using the iterative process as outlined by Creswell (2014) and the data was reviewed by the researcher again and again to ensure its consistency and properly understood for interpretation. Finally, the researcher used the member checking methods which were identified by Creswell (2014) to check the accuracy of the information transcribed to words.

\section{Results}

\section{A. Competency of Supervisors as a Change Agent}

Among the roles to be played by school supervisors, they are expected to change agents in the school, who lead and facilitate the transformation and improvement of schools on a varieties educational programs developed and implementing in the school systems; which is one of the dimensions of supervision this study focused. So, some of the variables of skills to be possessed by supervisors in the form questions were forwarded to teachers and principals and analyzed as follows.

Table 1: Respondents Views Regarding the Competency of Supervisors as a Change Agent

\begin{tabular}{|c|c|c|c|c|c|c|c|c|}
\hline & \multirow[b]{2}{*}{ My school supervisor: } & \multirow[b]{2}{*}{ Respondent } & \multirow{2}{*}{$\begin{array}{l}\text { Mean } \\
\overline{\mathbf{x}}\end{array}$} & \multirow{2}{*}{$\begin{array}{l}\text { Standard } \\
\text { Deviation }\end{array}$} & \multicolumn{4}{|c|}{ Overall } \\
\hline & & & & & $\overline{\mathbf{x}}$ & SD & $\mathrm{p}$-value & t-value \\
\hline \multirow{2}{*}{1} & \multirow{2}{*}{$\begin{array}{l}\text { investigate and adapt different } \\
\text { change programs to improve } \\
\text { school practices. }\end{array}$} & Teachers & 2.84 & 1.07 & \multirow{2}{*}{2.86} & \multirow{2}{*}{1.08} & \multirow{2}{*}{.22} & \multirow{2}{*}{-1.04} \\
\hline & & Principals & 3.00 & 1.14 & & & & \\
\hline \multirow{2}{*}{2} & \multirow{2}{*}{$\begin{array}{l}\text { has skills to advocate different } \\
\text { change programs and has a } \\
\text { long-range strategy for schools } \\
\text { effectiveness }\end{array}$} & Teachers & 2.91 & 1.16 & \multirow{2}{*}{2.91} & \multirow{2}{*}{1.16} & \multirow{2}{*}{.46} & \multirow{2}{*}{0.18} \\
\hline & & Principals & 2.88 & 1.17 & & & & \\
\hline \multirow[t]{2}{*}{3} & \multirow{2}{*}{$\begin{array}{l}\text { has skills to manage compelling } \\
\text { vision of the change he/she } \\
\text { wants to see in the future }\end{array}$} & Teachers & 2.85 & 1.11 & \multirow{2}{*}{2.86} & \multirow{2}{*}{1.14} & \multirow{2}{*}{.001} & \multirow{2}{*}{-.62} \\
\hline & & Principals & 2.95 & 1.30 & & & & \\
\hline \multirow[t]{2}{*}{4} & \multirow{2}{*}{$\begin{array}{l}\text { can encourage the people who } \\
\text { can make the change and } \\
\text { provides support for them }\end{array}$} & Teachers & 2.92 & 1.08 & \multirow{2}{*}{2.94} & \multirow{2}{*}{1.08} & \multirow{2}{*}{.399} & \multirow{2}{*}{-.81} \\
\hline & & Principals & 3.04 & 1.13 & & & & \\
\hline
\end{tabular}




\begin{tabular}{|c|c|c|c|c|c|c|c|c|}
\hline \multirow{2}{*}{5} & \multirow{2}{*}{$\begin{array}{l}\text { can facilitate and engage team } \\
\text { members who will need to the } \\
\text { change }\end{array}$} & Teachers & 2.85 & 1.08 & \multirow{2}{*}{2.88} & \multirow{2}{*}{1.09} & \multirow{2}{*}{.249} & \multirow{2}{*}{-1.37} \\
\hline & & Principals & 3.06 & 1.13 & & & & \\
\hline \multirow{2}{*}{6} & \multirow{2}{*}{$\begin{array}{l}\text { can diagnose problems and } \\
\text { advise with change initiatives } \\
\text { from different perspectives }\end{array}$} & Teachers & 2.70 & 1.00 & \multirow{2}{*}{2.74} & \multirow{2}{*}{1.03} & \multirow{2}{*}{.001} & \multirow{2}{*}{-1.84} \\
\hline & & Principals & 2.96 & 1.21 & & & & \\
\hline \multirow[t]{2}{*}{7} & \multirow{2}{*}{$\begin{array}{l}\text { has skills to create new and } \\
\text { better ways of doing things to } \\
\text { enhance the school success }\end{array}$} & Teachers & 2.79 & 1.09 & \multirow{2}{*}{2.85} & \multirow{2}{*}{1.10} & \multirow{2}{*}{.448} & \multirow{2}{*}{-2.41} \\
\hline & & Principals & 3.16 & 1.11 & & & & \\
\hline
\end{tabular}

Source: Survey questionnaire $\left(N=381\right.$, Significance difference at ${ }^{\propto}=0.05$ with the degree of freedom 380).

Concerning skills of the school supervisors investigate and actively adapt different change programs to improve school practices $(\mathrm{M}=2.86$, $\mathrm{t}$-value $=-1.04)$; and those supervisors have skills to advocate different change programs with long-range strategies for schools effectiveness $(\mathrm{M}=2.91$, $\mathrm{t}$-value $=0.18)$. This result disclosed that the majority of supervisors working in the schools who participated in this study have limited competencies in adopting and advocating different change programs. In the same way, the P-value in table 1 for the two variables indicated above exceeds the significance level of $(\mathrm{P}=.229>0.05$ and $\mathrm{P}=.468>0.05)$ respectively. These statistical results revealed that there is no significant difference in the perceptions of the two groups.

In terms of skills supervisors have to manage compelling vision of change a supervisor wants to see in the future $(\mathrm{M}=2.86, \mathrm{t}=-.629)$ and able to encourage people who can make change $(\mathrm{M}=2.94, \mathrm{t}=-.817)$; this statistical result revealed that many of supervisors working in sampled schools have lack of competencies to manage compelling vision of change in the future. The $\mathrm{P}$-value for variables in item 3 is less than the significance level of $(\mathrm{P}=.001<0.05)$ indicates that there is a significant difference in perception between the two groups. Contrary to item 4 , the $\mathrm{P}$-value is greater than the significance level of $0.05(\mathrm{P}=.399>0.05)$ indicates that there are no differences in perceptions between the two groups.

Among the skills supervisors have to facilitate and engage team members who will need to the change $(\mathrm{M}=2.88, \mathrm{t}=-1.37)$ and able to diagnose problems on change initiatives $(\mathrm{M}=2.74$, $\mathrm{t}=-1.84)$; this result reveals that majority of supervisors working in the schools participated in this study have limited competencies to facilitate change and able to diagnose problems on change programs. In the same way, he P-value for variables in item 5 is more than the significance level of $(\mathrm{P}=.249>0.05)$ which indicates there is no perception between two groups. Contrary to item 6 , the $\mathrm{P}$-value is less than the significance level $(\mathrm{P}=.001<0.05)$ which indicates that there are differences in perceptions between two groups. Respondents are also indicated that, skills required for supervisors to create new and better ways of doing things to enhance school success $(\mathrm{M}=2.85, \mathrm{t}=-2.41)$. Since the P-value (.448) exceeds the significance level of $0.05(\mathrm{P}=.448>0.05)$ which indicates that there are differences in perceptions between two groups.

\section{B. Competencies of Supervisors' in Promoting Positive School Culture}

Another dimension of supervision tried to see in this study was the competency and roles to be played by supervisors in promoting positive school cultures. In this regard, some questions were forwarded to teachers and principals and analyzed as follows. 
Table 2: Competencies of Supervisors' in Promoting Positive School Culture

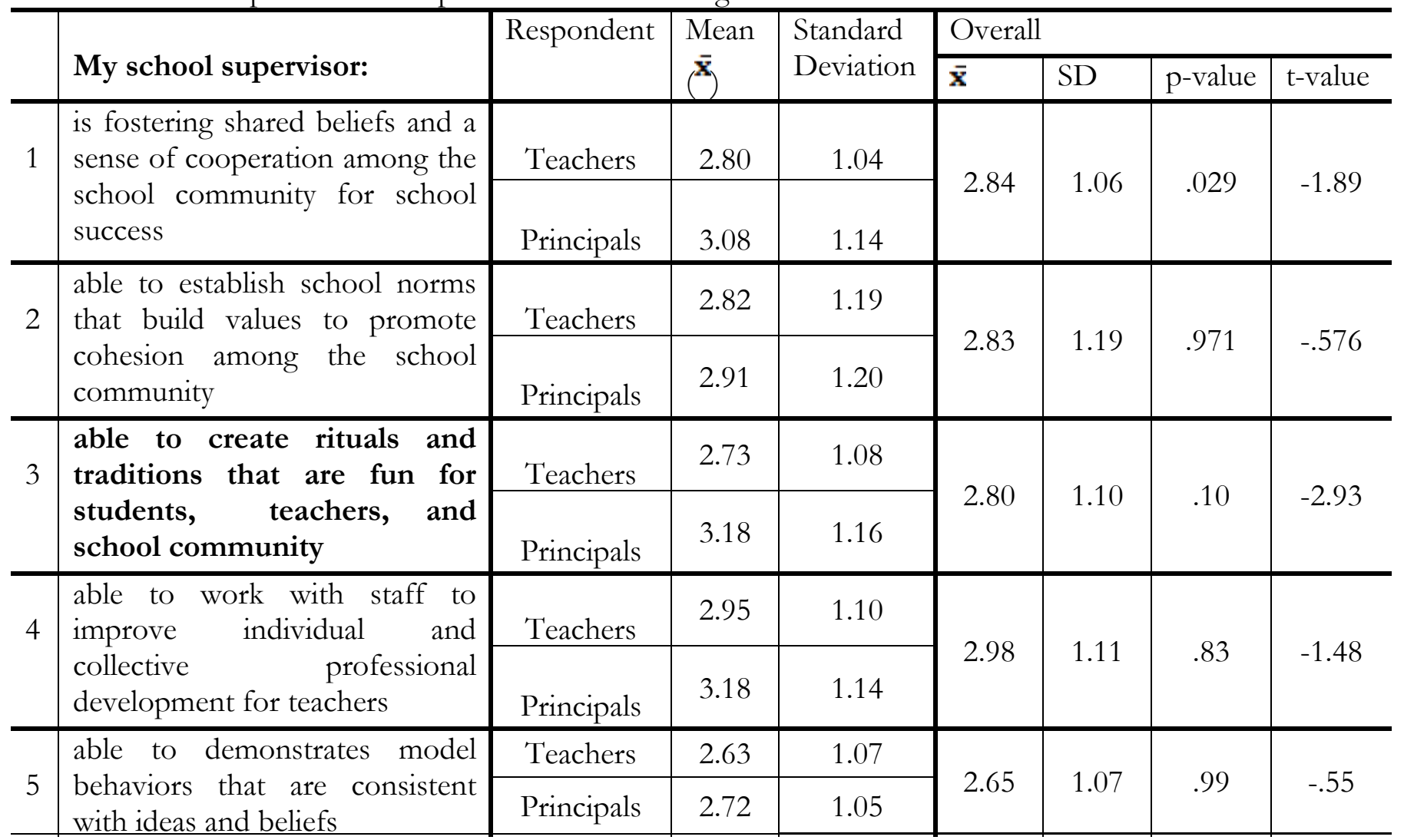

Source: Survey questionnaire $\left(N=381\right.$, Significance difference at ${ }^{\propto}=0.05$ with the degree of freedom 380).

In terms of the competencies of supervisors in foster shared beliefs and a sense of cooperation among school community for school success $(\mathrm{M}=2.84$, $\mathrm{t}$-value $=-1.89)$; as well as, those supervisors establish school norms that build values to promote cohesion among school community $(\mathrm{M}=2.83$, $\mathrm{t}$-value $=-.576)$. As a result, indicated, the majority of supervisors working in the schools participated in this study demonstrated minimum skills in foster shared beliefs and a sense of cooperation among the school community. They have also limited in capacity of establishing school norms that build values to promote cohesion among the school community. Similarly, the $\mathrm{P}$-value in above table 2 in two variables exceeded the significance level of $(\mathrm{P}=$ $.029>0.05$ and $\mathrm{P}=.971>0.05)$ respectively. These statistical results revealed that there is no significant difference in perceptions between the two groups.

With regards to the competencies of supervisors in creating rituals and traditions that are fun for students, teachers and school community $(\mathrm{M}=2.80$, $\mathrm{t}$-value $=-2.93)$; and able to work with staff to improve individual and collective professional development for teachers $(\mathrm{M}=2.98, \mathrm{t}=$ 1.48). As the result indicated the majority of respondents agreed that many supervisors have a shortage of competencies in create rituals and traditions for the school community, and are also weak in proficient to improve individual and collective professional development for teachers. The $\mathrm{P}$-value for variables in item 3 is more than the significance level of $(\mathrm{P}=.10>0.05)$ which indicates there is no perception between two groups. Likewise, in item 4, the P-value is more than the significance level $(\mathrm{P}=.83>0.05)$ which indicates that there are no differences in perceptions between two groups. In table 2 , Item 5 , respondents are also indicated that the competency of supervisors demonstrates model behaviors that are consistent with ideals and beliefs $(M=2.65, t=-.559)$. Since the P-value (.996) exceeds the significance level of $0.05(\mathrm{P}$ $=.996>0.05)$ which indicates that there are no differences in perceptions between the two groups. 


\section{Competency of Supervisors' on Application of Supervision Principles}

One of the dimensions of supervision tried to see in this study is the competencies of supervisors in the application of common supervision principles in the specific context to which they are working to improve the quality of instruction. Thus, based on this assumption some questions were posed to the teachers and principals and analyzed in the following table 3.

Table 3: Competencies Supervisors on Application of Supervision Principles

\begin{tabular}{|c|c|c|c|c|c|c|c|c|}
\hline & \multirow[b]{2}{*}{ My school supervisor: } & \multirow[b]{2}{*}{ Respondent } & \multirow{2}{*}{$\begin{array}{l}\text { Mean } \\
\overline{\mathbf{x}^{\prime}}\end{array}$} & \multirow{2}{*}{$\begin{array}{l}\text { Standard } \\
\text { Deviation(SD }\end{array}$} & \multicolumn{4}{|c|}{ Overall } \\
\hline & & & & & $\overline{\bar{x}}$ & $\mathrm{SD}$ & $\mathrm{p}$-value & t-value \\
\hline \multirow[b]{2}{*}{1} & \multirow{2}{*}{$\begin{array}{l}\text { helps teachers to be creative } \\
\text { and innovative in their } \\
\text { methodology of teaching }\end{array}$} & Teachers & 2.68 & 1.14 & \multirow[b]{2}{*}{2.83} & \multirow[b]{2}{*}{1.08} & \multirow[b]{2}{*}{.307} & \multirow[b]{2}{*}{.158} \\
\hline & & Principals & 2.72 & 1.21 & & & & \\
\hline \multirow{2}{*}{2} & \multirow{2}{*}{$\begin{array}{l}\text { makes supervision democratic } \\
\text { and provide the opportunity } \\
\text { for teachers to express their } \\
\text { ideas }\end{array}$} & Teachers & 2.95 & 1.05 & \multirow[b]{2}{*}{2.81} & \multirow[b]{2}{*}{1.14} & \multirow[b]{2}{*}{.102} & \multirow[b]{2}{*}{-1.99} \\
\hline & & Principals & 3.31 & 1.00 & & & & \\
\hline \multirow[t]{2}{*}{3} & \multirow{2}{*}{$\begin{array}{l}\text { makes } \\
\text { theoretically supervision } \\
\text { ultimate values, aims, and } \\
\text { policies }\end{array}$} & Teachers & 2.90 & 1.07 & \multirow{2}{*}{2.72} & \multirow{2}{*}{1.12} & \multirow{2}{*}{.212} & \multirow{2}{*}{-.329} \\
\hline & & Principals & 3.31 & 1.10 & & & & \\
\hline \multirow[t]{2}{*}{4} & \multirow{2}{*}{$\begin{array}{lcr}\text { makes } & \text { supervision } & \text { be } \\
\text { scientific } & \text { which } & \text { apply } \\
\text { systematic } & \text { and } & \text { critical } \\
\text { methods } & & \end{array}$} & Teachers & 2.72 & 1.21 & \multirow{2}{*}{2.83} & \multirow{2}{*}{1.14} & \multirow{2}{*}{.004} & \multirow{2}{*}{-.093} \\
\hline & & Principals & 3.01 & 1.28 & & & & \\
\hline \multirow[b]{2}{*}{5} & \multirow{2}{*}{$\begin{array}{l}\text { respects personality and } \\
\text { individual differences among } \\
\text { teachers in the school }\end{array}$} & Teachers & 2.75 & 1.10 & \multirow[b]{2}{*}{2.76} & \multirow[b]{2}{*}{1.11} & \multirow[b]{2}{*}{.060} & \multirow[b]{2}{*}{-1.56} \\
\hline & & Principals & 2.68 & 1.07 & & & & \\
\hline \multirow[b]{2}{*}{6} & \multirow{2}{*}{$\begin{array}{l}\text { provides the opportunity for } \\
\text { teachers to exercise their } \\
\text { originality }\end{array}$} & Teachers & 2.86 & 1.11 & & & & \\
\hline & & Principals & 3.22 & 1.16 & 2.87 & 1.12 & .097 & -1.05 \\
\hline & promotes cooperation among & Teachers & 2.88 & 1.11 & & 111 & רחס & 106 \\
\hline 7 & all staffs in the school & Principals & 3.09 & 1.22 & 2.66 & 1.10 & .002 & -1.90 \\
\hline
\end{tabular}

Source: Survey questionnaire $\left(N=381\right.$, Significance difference at ${ }^{\propto}=0.05$ with the degree of freedom 380).

Concerning competency of supervisors helps teachers to be creative and innovative in their methodology of teaching $(\mathrm{M}=2.83$, $\mathrm{t}$-value $=.158)$; and those supervisors have skills to makes supervision democratic and provide opportunity for teachers express their ideas $(M=2.81$, t-value $=-1.99)$ indicates two groups of respondents agreed that, supervisors have limited competency in applying identified principles in the schools they are assigned. Since the P-value in table 3 for the two variables indicated above is exceeds the significance level of $(\mathrm{P}=.307>0.05$ and $\mathrm{P}=.102>0.05)$ respectively. These statistical results revealed that there is no significant difference in the perceptions of the two groups.

In terms of the competency of supervisors makes supervision theoretically sound with ultimate values, aims and policies $(\mathrm{M}=2.72, \mathrm{t}$-value $=-.329)$; also supervisors have skills to makes supervision be scientific which apply systematic and critical methods $(\mathrm{M}=2.83$, $\mathrm{t}$-value $=$ - 
.093) indicates two groups of respondents somewhat agreed that supervisors have inadequate competency in applying identified principles in the schools they are working. Since the P-value in table 3 for item 3 is exceeds the significance level of $(\mathrm{P}=.212>0.05)$; but, it is less than for item $4(\mathrm{P}=.004<0.05)$. These statistical results revealed that there is a difference in opinions between the two groups.

With regards to the competencies of supervisors respect personality and individual differences among teachers in the school $(\mathrm{M}=2.76$, $\mathrm{t}$-value $=-1.56)$; and able to provides opportunities to teachers to exercise their originality $(\mathrm{M}=2.87, \mathrm{t}=-1.05)$ revealed that, supervisors are less proficient in applying the principles to respect personality and individual differences of teachers, and provides opportunities to teachers to exercise their talents. The Pvalue for variables in items 5 and 6 is more than the significance level of $(\mathrm{P}=.060>0.05)$ and $(\mathrm{P}$ $=.097>0.05)$ indicates there are no differences in perception between two groups. In the same way for the variable in item 7 , supervisors promote cooperation among all staffs in the school both groups of respondents indicated that competency of supervisors promote cooperation among all staffs $(\mathrm{M}=2.66, \mathrm{t}=-1.96)$ with the P-value (.002) which is less than the significance level of 0.05 indicates that there are differences in perceptions between two groups.

\section{Discussions}

Today schools in the glob under a continuous process of change and transformation; because of the dynamic nature of education with globalization and global competition to cultivate educated citizens to satisfy the needs of society. In this regard, there will always be new and improvable issues to have emerged in the education system. Change is a phenomenon that is inevitable in schools, which are faced with new demands and circumstances of the changing education system. In the process of change and transformation, the new ways of organizing and working school arrangements involving relationships, understandings, and processes in which people are employed. According to Louis Pasteur (1854) "Chance favors only the prepared mind"; this indicates that supervisors in educational organizations should have always open mind which is prepared for change; because educational organizations are always in the pressure of change process to sustain and exist in the process of globalization.

When we are talking about the change in the field of education, supervisors as a change agent are always on the leading positions to bring change in the system; because they are supervisors who have ultimate responsibilities to oversee all of the change processes and the developmental aspects of the education system. In this regard, I am forwarded different roles to be played by supervisors in the three basic dimensions to which the study's focused namely change agent, an advocate of positive school cultures and apply sound principles of supervision discussed as follows.

In the processes of education, supervision service is the lifeblood that stimulates the professional growth of teachers and principals to achieve broad goals of education. Depending on the nature of supervision activities, one of the primary roles of supervisors is that they should be change agents for the educational goal attainment in general and school goal attainment in particular. This is because; change in education is a constant process that needs supervisory supports in primary and secondary school.

As discussed in the result section, primary and secondary school teachers and principals asked some of the roles to be played by their supervisors to influence change processes. But most of the respondents indicated that their supervisors have limited competency and skills in investigating change programs. In addition to quantitative information gathered, the interview conducted with some primary and secondary school principals and senior teachers indicated that 
almost all of the supervisors are engaged with administrative duties and collection of information rather than supporting teachers and school principals on pedagogical tasks. In this regards, one of my interviewees from senior teachers stated that:

"... who is supervisor inspiring us towards change and school improvement, ... In my opinion, supervisors are hired for collecting information about school activities. Most of the supervisors came to my school focused on administrative activities and hidden political missions. Is it the responsibility of supervisors to investigate and facilitate change programs in the school? In my career life, I didn't know a supervisor who has a plan as a change agent inspires me towards change programs and initiatives..."

Another important issue I want to discuss is that, as liaison agent school supervisors should act as advocators of every educational change for those who may be affected by the change process. For supervisors encourage people to apply the change and school reform is among vital roles. But in the schools undergoing this study, supervisors didn't demonstrate advocacy skills for changes to be happening in the schools they are working in. In this regards, one of my interviewees from school principals stated that:

" ... most of the time my cluster supervisor asked me the same information when he has visited my school; nothing is raised by a supervisor about novel ideas and change initiatives to improve my school activities; ..."

One of the key activities of the supervisor for transforming schools towards a more advanced level is finding new ways of doing things for teachers to improve the instruction provided in the school. A supervisor as change agents clarify the change initiatives and make them easy to implement. As a facilitator of the change process, school supervisors are expected to plan for change with available resources to enable teaching and administrative staff to be successful as they go through the change process.

Although supervisors are working in the schools undergoing in this study providing their efforts to facilitate the schools activities, they have limited competencies on the areas like to adapt and advocate different change programs, skills to manage compelling vision with longrange strategy for schools effectiveness, skills to facilitate and engage team members who will need to the change, diagnose problems and advise with a change initiatives from different perspectives and should have skills to create new and better ways of doing things to enhance the school success and improvement.

To sum up, the school supervisors who are working in primary and secondary schools of Sidama Zone should have goals, targets, and due dates for the change and school reform. This is because successful school reform and change depend on supervisors who have direct skills to lead, support and execute change programs with people who are working with them. In this regard, almost all of the informants who participated in the interview noted that they want to bring change and improvement in their school, especially on the teaching and learning process; but, they need a potential supervisor who leads and guide them towards change and improvement. An effective supervisor knows that their support is crucial to success and commit to doing their part.

Another important dimension this study focused on is on supervisory roles to promote positive school culture. School culture is the set of beliefs, values, and assumptions the school communities commonly shared to realize the school vision. A school culture consists of the underlying influences and attitudes within the school based on the norms, traditions, and beliefs 
of the staff and students. The prevailing atmosphere in the school will affect everything that is going on inside and around the school. Although efforts made by a few supervisors to promote positive culture among schools passed through this study, the majority of supervisors were not proficient in building positive school cultures. In this regard, the finding of this study indicated that in the schools undergoing this study the supervisors didn't play roles to create meaningful school culture among the school community. To promote positive school culture school supervisors create a network between and among all stakeholders and design framework which is used as a blueprint for the achievement of all school activities and educational programs in the schools.

In terms of the competencies of supervisors in establish school norms that build core values for school reform and success; supervisors working in the schools participated in this study didn't have the competency to create school norms that build core values for school success. Likewise, it is supervisory roles in creating positive rites and customs for the benefits of all school community in general and student and teacher in particular; because, the existences of such trends in the schools will help teachers and students engage in varieties co-curricular activities and events used to build morale for the school community. However, the majority of supervisors who are working in the schools participated in this study didn't have the competency to create rituals and traditions that are used to promote positive school cultures.

As a staff development director, it is a supervisor who facilitates professional development for teachers. Supervisors should have knowledge and skills in guiding and supporting teachers to develop their professional expertise in the field of education. In this regard, supervisors should organize and facilitate professional development activities for teachers and the entire staff at the school; because the presence of this type of culture in the schools helps teachers and other staff to be fully aware of their career development. Also, it's good to make sure that the supervisor as the leaders are aware of what their staff thinks and feels in their work. Set up regular times to ask for feedback, hear out concerns, and get suggestions for improvement of a career in the staff professional life. Supervisors should design strategies for staff development and assistance to teachers in improving both personal and professional qualities, and then instructional development becomes a by-product of staff development. School supervisors should have lists of qualities and values that they want to see in their teachers and students. All changes have to start from the top. That means when a supervisor interacts with teachers and students, she/he needs to be an example of the behavior that she/he wants to see in her/his school. Hence, supervisors who are working in the schools who participated in this study didn't have the competency to enhance the professional development of teachers and the entire staff.

It is obviously recognized that, to effectively and efficiently deliver supervision services; supervisors should have knowledge and skills on how to apply different principles of supervision depending on the contexts to which the schools exist. In this regard, different supervision principles developed by Ayer \& Barr (1928) are presented to respondents whether their school supervisors apply in the real situations of their schools. The competencies of supervisors in applying such supervisory principles are below expected standards. It is believed that, supervision should be theoretically sound; sensitive to ultimate values, aims, and policies with special reference to their adequacy; be sensitive to change and development, hence supervisors should constantly re-evaluate materials and methods in terms of changing values, clarified aims and policies. But supervisors working in the schools who participated in this study were not applying this principle. 
In terms of the principles to be applied by school supervisors such as supervision should be scientific; it should employ orderly, systematic, critical methods in studying, improving and evaluating anything within its province, including its materials and procedures. It should drive and use data and conclusions which are constantly more objective, precise, sufficient, impartial, expertly secured, and systematically organized. But supervisors working in the schools who participated in this study did not also apply this principle.

It is also expected that supervision should be democratic; in this regards supervisors should provide full opportunity to their staff for cooperation and participation, inviting all to contribute. Supervision should be also creative; it should see latent talents; provide an opportunity for the exercise of originality and the development of unique contributions. Supervision service is also attitudinal; as this principle, the attitude of the supervisor and his ability to develop wholesome and constructive attitudes in co-workers determines the effectiveness of supervision activities. Hence, supervisors who are working in the schools who participated in this study didn't demonstrating competency to apply different principles of supervision.

\section{Conclusion}

The purpose of this study was to scrutinize competencies and roles of supervisors in primary and secondary schools of Sidama zone with referring the three dimensions of supervision in consideration of supervisors as change agent, builders of positive school cultures and implementers of different supervisory principles depending on the specific contexts to which the schools operate their day to day activities at the study areas. However, the findings of the study revealed that the majority of school supervisors working in the school understudied have limited competencies on the dimensions like considering supervisor as a change agent, creating positive school culture and application of different supervisory principles in the context to which they are working. Finally, based upon the findings it was concluded that improving the professional competence of supervisors has immense contribution in enhancing school improvement, reform and creating a positive school culture and change, as a result, the quality of education in primary and secondary schools will be improved. In the light of these results, there should have legal policies and initiation for distinguished individuals like school principals, senior teachers to come to supervisory position; there should have also found training courses for supervisors on the contemporary issues of global education, supervision trends to build their skills; and there should have standard supervision manuals for school supervisors aimed to improve their day to day supervisory activities.

\section{Recommendation}

In the light of the findings, I recommend (1) there should have legal policies and initiation for distinguished individuals like school principals, senior teachers to come to supervisory position in primary and secondary schools, (2) there should have training courses and workshops for supervisors on the contemporary issues of global education, supervision trends to build their skills; and (3) develop and provide standard supervision manuals for school supervisors so that they can use the material to improve their day to day supervisory activities.

\section{References}

Ayer, F. C., \& Barr, A. S. (1928). The organization of supervision: An analysis of the organization and administration of supervision in city school systems. New York: D. Appleton \& Co.

Best, J. W., \& Kahn, J. V. (2003). Research in Education (8 ${ }^{\text {th }}$ Ed.). MA: A Viacom Company.

Boardman, C. (1993). Democratic supervision in secondary schools. Massachusettes: Hereghter Mifflin Co.

Certo, S. C. (2006). Supervision: Concepts and skill building (5 ${ }^{\text {th }}$ ed). McGraw-Hill /Irwin, United States. 
Creswell, J. W. (2014). Educational Research: Planning, Conducting, and Evaluating Quantitative and Qualitative Research (4th ed.). Upper Saddle River R J: Pearson Education.

Daresh, J. C. (2001). Supervision as proactive leadership. Boston: Waveland Press.

Ethiopian Ministry of Education. (1994). Educational supervision manual. Addis Ababa: EMPDA.

Gay, L. R., Mills, G. E., \& Airasian, P. (2009). Educational Research: Competencies for Analysis and Applications. New Jersey: Pearson Education, Inc.

Gregory, C. F. (2011). Institutional supervision: A descriptive study focusing on the observation and evaluation of teachers in cyber schools, Pennsylvania (Published Doctoral dissertation), Indiana University, USA.

Habtamu G., and Eshetu M. (2019). Analysis of the supervisory support to teachers in primary and secondary schools of Sidama zone, Ethiopia. Journal of Humanities and Social Science, 24(10), 45-51.

International institute of educational planning IIEP/UNESCO. (2007). Reforming school supervision for quality improvement: Module 1: Supervision: a key component of a quality monitoring system. Paris: IIEP/UNESCO.

Kendall, L. (2008). The conduct of qualitative interview: Research questions, methodological issues, and researching online. In J. Coiro, M. Knobel, C. Lankshear \& D. Leu (Eds.), Handbook of research on new literacies (pp. 133-149). New York: Lawrence Erlbaum Associates.

Kotirde, Y., \& Bin, J. (2014). The supervisor's role for improving the quality of teaching and learning in Nigeria secondary school educational system. International Journal of Education and Research, 2(8), 53-60.

Pasteur, L. (1854). Louis Pasteur Quotes. Retrieved from https://en.wikiquote.org/wiki/Louis_Pasteur.

Nolan, J. F., \& Hoover, L. A. (2008). Teacher supervision and evaluation: Theory in to practice (2nd ed.). Hoboken, NJ: John Wiley \& Sons, Inc.

Sergiovanni, \& Starratt, R. J. (2007). Supervision: A Redefinition. New York, NY: McGraw-Hill Companies Inc.

Starratt, R. J. (2008). Supervision of instruction - the history of supervision, roles and responsibilities of supervisors. Issues trends and controversies, Education Encyclopaedia. Retrieved from https://education.stateuniversity.com/pages/2472/Supervision-Instruction.html.

Sule, M. (2013). The influence of the principals' supervisory demonstration strategy on teacher's job performance in Nigeria secondary schools. Journal of Humanities and Social science 2(1), 39-44.

Unal , A., \& Erol , S . Y. (2011). The expectations of primary school principals from primary school supervisions. Journal of New World Sciences Academy, 6(4), 2631-2645.

World Bank. (2010). Supervision and support of primary and secondary education: policy note for government of Poland. Knowledge brief. Retrieved from http:/ www.worldbank.

UNESCO. (2007). Reforming school supervision for quality improvement. Retrieved from https://unesdoc.unesco.org/ark:/48223/pf0000215935. 